\title{
Pensando a inclusão que temos para tecer a inclusão que queremos: refletindo sobre a reorientação político- pedagógica do PME de Itaguaí/RJ
}

Thinking about the inclusion that we have, to weave the inclusion that we want: reflecting about the political-pedagogical reorientation of the PME (Municipal Plan of Education) of Itaguaí/RJ

Pensando la inclusión que tenemos para tejer la inclusión que queremos: reflexionando sobre la reorientación político-pedagógica del PME de Itaguaí/RJ

\section{* Patrícia Ferreira de Andrade}

Mestre pela Universidade Federal Rural do Rio de Janeiro (UFRRJ), Rio de Janeiro, Brasil. pat.fandrade@gmail.com - https://orcid.org/0000-0002-8878-1395

\section{** Allan Rocha Damasceno}

Professor doutor na Universidade Federal Rural do Rio de Janeiro, Seropédica, Rio de Janeiro, Brasil. lepedi-ufrrj@hotmail.com

\section{Recebido em 06 de maio de 2018}

Aprovado em 09 de novembro de 2018

Publicado em 06 de maio de 2019

\section{RESUMO}

Este artigo tem como objeto de investigação o Plano Municipal de Educação de Itaguaí/RJ, que foi reformulado no ano de 2015, com validade até o ano de 2025. Para tal, tomando conhecimento da relevância do PME (2015) de Itaguaí, no que se refere a reorientação da educação do Município, este estudo teve como objetivo pesquisar qual meorientação inclusiva está instituída para 0 atendimento pedagógico e educacional dos estudantes público-alvo da Educação Especial do Município. Neste sentido, como procedimento metodológico realizamos análise documental que consistiu na reflexão acerca do vigente Plano Municipal de Educação de Itaguaí. A concepção metodológica desta pesquisa se fundamenta na indissociabilidade entre teoria e método posta na Teoria Crítica da educação. O pensamento de Theodor Adorno (1995) subsidiou nossas análises, assim como as reflexões de Damasceno (2006) e Costa (2010), comentadores de seu pensamento. Identificamos que o PME (2015) representa uma significativa conquista para a educação do município, pois apresenta disposições político-pedagógicas que colaboram com a inclusão escolar de estudantes público-alvo da Educação Especial. Assim, torna-se urgente que o instituído no PME (2015) se implemente na esfera instituinte dos movimentos democráticos desta rede de ensino. 
Palavras-chave: Plano Municipal de Educação de Itaguaí; Inclusão; Educação Especial.

\section{ABSTRACT}

This article aims at investigating the Plano Municipal (Municipal Plan) from Itaguai/RJ, which was reformulated in the year 2015 and will be current until the year 2025. For this purpose and firstly acknowledging the relevance of the PME (2015) from Itaguai in what is related to the re-orientating the education in the municipality; this study had the objective of researching which inclusive reorientation is instituted for the pedagogical and educational assistance of the target-public students of the special education program of the municipality. In this sense as a methodological procedure we carry out a documental analysis that consisted the reflection of the current Plano Municipal de Educação de Itaguaí (Municipal Plan of Education of Itaguaí). The methodological conception of this research was founded in the inseparability between method and theory exposed in the Teoría Critica (Critical Theory) of education. The thought of Theodor Adorno (1995) inspired our analysis, as well as Damasceno (2006) and Costa (2010), commentators of his thought. We identified that the PME (2015) represents a very important achievement for the education of the municipality, since it presents political-pedagogical disposals that enhance the school inclusion of the target-public students of special education. Therefore it has become urgent that what was instituted by the PME (2015) is implemented in the institutive sphere of the democratic movements of this ensino network.

Keywords: Municipal Education Plan of Itaguai; Inclusion; Special Education

\section{RESUMEN}

Este artículo tiene como objetivo de investigación el Plan Municipal de Educación de Itaguaí/RJ, que fue reformulado en el año 2015 y tiene vigencia hasta el año 2025. Para tal, tomando conocimiento de la relevancia del PME (2015) de Itaguaí en lo que se refiere a la (re) orientación de la educación del municipio, este estudio tuvo como objetivo investigar cual reorientación inclusiva esta instituida para la atención pedagógica y educacional de los estudiantes público-objetivo de la Educación Especial del Municipio. En este sentido, como procedimiento metodológico realizamos un análisis documental que constituye una reflexión acerca del vigente Plan Municipal de Educación de Itaguaí. La concepción de la metodología de esta investigación se fundamenta en la "indisociabilidad" entre la teoría y el método expuestos en la Teoría Critica de la educación. El pensamiento de Theodor Adorno (1995) subsidió nuestros análisis, además de las reflexiones de Damasceno (2006) y Costa (2010), comentadores de su pensamiento. Identificamos que el PME (2015) representa una conquista significativa para la educación del municipio, pues presenta disposiciones político-pedagógicas que colaboran con la inclusión escolar de los estudiantes publicoobjetivo de la Educación Especial. Así, se torna urgente que lo instituido en el PME (2015) se implemente en la esfera instituyente de los movimientos democráticos de esta red de enseñanza.

Palabras clave: Plan Municipal de Educación Itaguaí; Inclusión ; Educación Especial. 


\section{Introdução}

Qual educação nós queremos? Uma educação na/para a diversidade, que acolhe todos os seus estudantes? Para vivenciar a resposta positiva deste último questionamento, precisamos fazer parte do processo contínuo de luta e mobilização pela inclusão em educação. Nesta perspectiva, faz-se necessário debater a escola que temos para implementarmos a escola que queremos. (DAMASCENO, 2012)

Para a implementação da Educação Inclusiva as instituições escolares não podem simplesmente preocupar-se com a efetivação de matrículas de seus estudantes. Apesar de importante, torna-se indispensável à materialização das condições necessárias para a superação das barreiras que dificultam o processo de ensino e aprendizagem desses estudantes.

A inclusão escolar de estudantes público-alvo da Educação Especial, além de ser amparada/legitimada por variadas políticas educacionais inclusivas, é coerente com o processo da democratização do ensino e da sociedade, no qual objetiva demandas específicas que vão ao encontro desses estudantes/indivíduos. Assim, discorrer sobre tal tema é demasiadamente necessário para a afirmação de uma sociedade emancipada e, por conseguinte, de uma educação para todos.

Precisamos refletir: para quê Políticas públicas de educação inclusiva? Pensar o "para quê" frente a objetivos, a priori educacionais, promove nosso direcionamento, pois faz termos ciência para aonde nossa educação está sendo conduzida, fazendo nos livrar de práticas inócuas. Desse modo, Adorno (1995, p.140) afirma que:

\footnotetext{
No instante em que indagamos: "Educacão - para quê?", onde este "para quê" não é mais compreensível por si mesmo, ingenuamente presente, tudo se torna inseguro e requer reflexões complicadas. E, sobretudo, uma vez perdido este "para quê", ele não pode ser simplesmente restituído por um ato de vontade, erigindo um objetivo educacional a partir do seu exterior. (ADORNO, 1995, p.140)
}

Dessa maneira, considerando que o Plano Municipal de Educação de Itaguaí/RJ foi reformulado no ano de 2015 e será vigente até o ano de 2025, temos o desejo neste artigo de pesquisar a reorientação político-pedagógica do atual PME no que tange ao atendimento pedagógico e educacional dos estudantes público-alvo da Educação Especial, pois reconhecemos que esse documento possui significância na orientação da educação do Município. 
O município de Itaguaí, lócus desta pesquisa, pertence ao Estado do Rio de Janeiro, e se encontra na região denominada Costa Verde, mas é um município que pertence a Baixada Fluminense. De acordo com o Instituto Brasileiro de Geografia e Estatística (IBGE), no ano de 2012 a estimativa de sua população era de 113.182 pessoas. A região limita-se, a oeste, com os municípios do Rio de Janeiro e de Seropédica; ao norte faz divisa com Piraí e Paracambi; a leste com os municípios Rio Claro e de Mangaratiba. Sua área estende-se por aproximadamente $272 \mathrm{~km}^{2}$, estando a uma altitude de 13 metros do nível do mar (PMEITAGUAí, 2015-2025), como podemos observar no mapa abaixo:

Figura 1- Município de Itaguaí

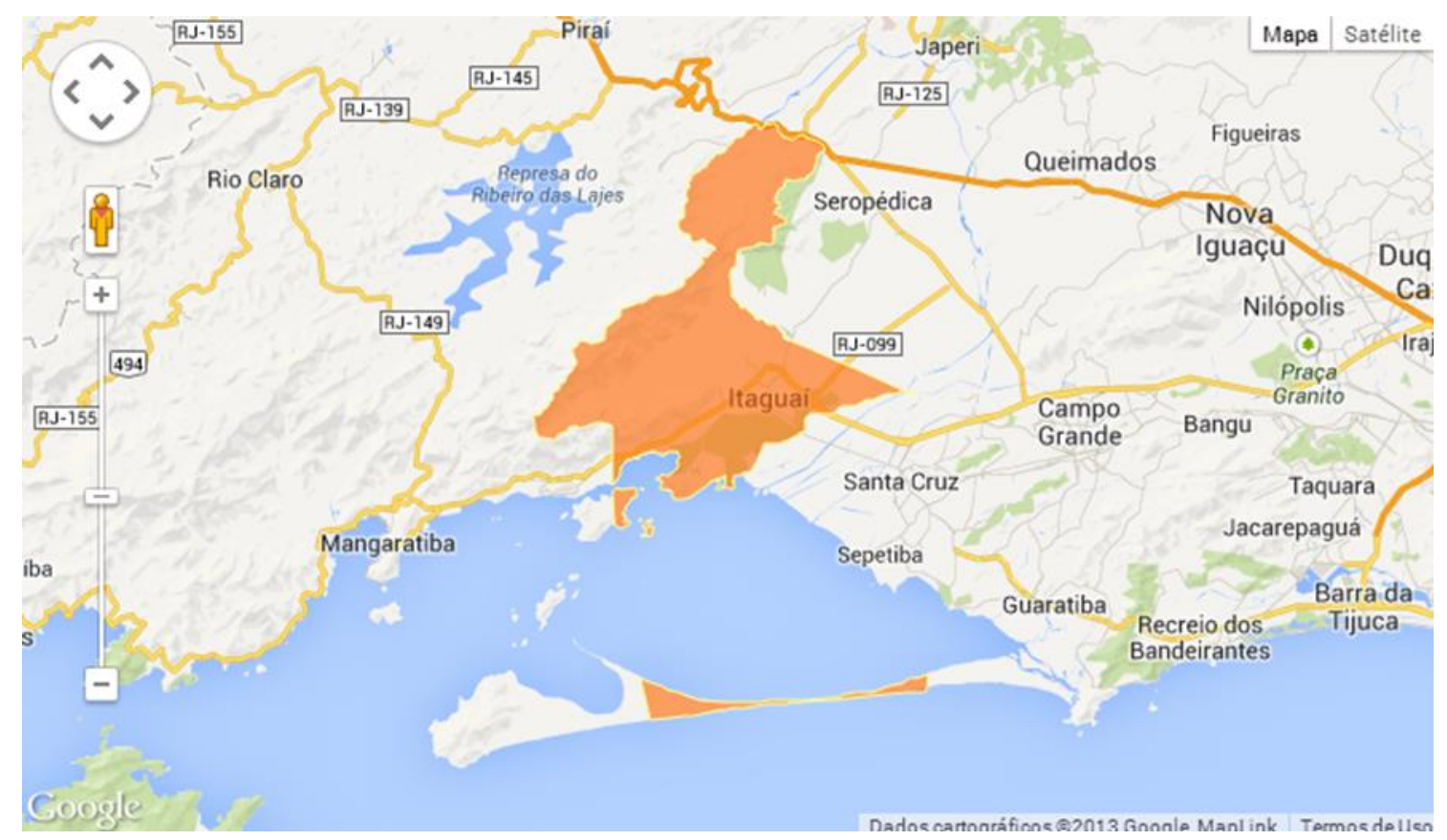

Fonte: http://www.ibge.gov.br/cidadesat/xtras/perfil.php?codmun=330200.

Itaguaí na atualidade é uma cidade em grande crescimento econômico, devido iniciativas privadas, principalmente quanto aos investimentos em seus portos. Diante dessa realidade, de acordo com o vigente Plano Municipal de Educação de Itaguaí (2015- 2025, p.21-22): "O município tem experimentado um crescimento econômico com a ascensão do Porto de Itaguaí e de empreendimentos na vizinhança, o que tem atraído novos moradores."

Debater o nosso objeto de estudo: atual Plano Municipal de Educação de Itaguaí/RJ (2015- 2025), frente à luz da Teoria Crítica, subsidiada pelos pensamentos do filósofo 
Theodor Adorno e de seus comentadores, nos possibilita pensar em uma educação para resistir à barbárie ${ }^{1}$ que se faz presente em nossas escolas.

Ao adotarmos a concepção teórico-metodológica da Teoria Crítica neste estudo, consideramos a relevância da crítica frente as nossas análises, pois na concepção adorniana não há indissociabilidade entre Práxis e Conhecimento. Assim, entendemos a Teoria Crítica da Educação como o próprio método desse estudo, de modo que, através da dimensão Teoria-Práxis, iremos refletir o conhecimento produzido in loco.

A proposta de uma educação livre e pensante deve estar intimamente ligada com a autorreflexão. O filósofo Adorno (1995) nos esclarece sua importância ao afirmar que significa o abandono da ingenuidade, como passagem para o humano. Reafirmamos que compreender a práxis, mas principalmente não dissociá-la do conhecimento teórico, é imprescindível para a ressignificação de pensamentos. Ainda em consonância com esta análise, Adorno (1995) completa afirmando que:

Dever-se-ia formar uma consciência de teoria e práxis que não separasse
ambas de modo que a teoria fosse impotente e a práxis arbitrária, nem
destruísse a teoria mediante o primado da razão prática, próprio dos primeiros
tempos da burguesia e proclamado por Kant e Fichte. Pensar é um agir, teoria
é uma forma de práxis; somente a ideologia da pureza do pensamento
mistifica este ponto. O pensar tem um duplo caráter: é imanentemente
determinado, estringente e obrigatório em si mesmo. Mas, ao mesmo tempo,
é um modo de comportamento irrecusavelmente real em meio à realidade.
Na medida em que o sujeito, a substância pensante dos filósofos, é objeto,
na medida em que incide no objeto, nessa medida, ele é, de antemão,
também prático. (ADORNO, 1995, p. $61.204-205$ )

Como procedimento de pesquisa realizamos uma análise documental, que consistiu em investigar o atual PME (2015-2025), de Itaguaí/RJ identificando se sua reorientação político-pedagógica é coerente com o processo de inclusão escolar de estudantes públicoalvo da Educação Especial.

Em um dos documentos do MEC (Ministério da Educação), denominado como "O Plano Municipal de Educação - Caderno de Orientações" aborda de forma minuciosa o que um Plano Municipal de Educação (PME) não deve deixar de tratar. Nesse sentido esse instrumento orientador explica que:

Os Planos Estaduais de Educação (PEEs) precisam ser imediatamente produzidos, debatidos e aprovados em sintonia com o PNE. E os Planos Municipais (PMEs), da mesma maneira que devem ser coerentes com o PNE,

\footnotetext{
${ }^{1} \mathrm{~A}$ barbárie se materializa nas escolas quando os integrantes da transformação educativa vivenciam uma educação que carece de práxis emancipatórias, de forma que não vislumbram um ensino humanizado de/e para todos.
} 
http://dx.doi.org/10.5902/1984686X32960

também devem estar alinhados aos PEEs dos estados a que pertencem. (BRASIL, 2014, p.6)

Ou seja, os Planos Municipais de Educação (PMEs) precisam estar em sintonia com os Planos Estaduais de Educação (PEEs) e com o Plano Nacional de Educação (PNE) (Lei 13.005/14). Nesta perspectiva, descrevemos o que concerne a este último, sobretudo ao atendimento dos estudantes público-alvo da Educação Especial.

O PNE no que tange aos estudantes público-alvo da Educação Especial, propõe em sua Meta 4 universalizar para a população de quatro a dezessete anos com deficiência, transtornos globais do desenvolvimento e altas habilidades ou superdotação, o acesso a Educação Básica e ao AEE (Atendimento Educacional Especializado), preferencialmente na rede regular de ensino, com a garantia de sistema educacional inclusivo, de salas de recursos multifuncionais, classes, escolas ou serviços especializados público ou conveniados (BRASIL, 2014).

Retornando ao Caderno de Orientações do MEC (2014) acerca do Plano Municipal de Educação observou-se que o trabalho do mesmo pressupõe o envolvimento das três esferas de gestão: federal, estadual e municipal. Entretanto, o documento afirma ainda que “(...) é fundamental considerar que o PME deve ser do município, e não apenas da rede ou do sistema municipal." (BRASIL, 2014, p. 7)

É relevante que se instigue a presença de todos os atores da ação educativa para a elaboração do PME. Sendo assim, o Caderno de Orientações do MEC, que direciona os PMEs aponta que:

Cabe aos gestores dos sistemas e das redes de ensino, sobretudo às Secretarias de Educação ou órgãos específicos, em colaboração com os Conselhos e Fóruns de Educação, a adoção de mecanismos, processos e ações para estruturar uma metodologia e uma agenda de trabalho que favoreçam os processos de participação e de decisão coletivos. (BRASIL, 2014, p.12)

Como foi visto, além do Plano Municipal de Educação construir metas em coerência com o PEE, serve como um instrumento de forte auxílio na organização do sistema educacional do Município, devido sua função de promover normas e ações com base na realidade educacional, econômica, social e cultural que o município presencia.

Dada à relevância desse documento, fica patente a influência que o PME possui na educação do município. Sendo assim, pensando na democratização tanto da sociedade quanto do ensino, ressaltamos a importância da reflexão frente à esse dispositivo que orienta/direciona a educação. 


\title{
Qual reorientação inclusiva político-pedagógica do município de Itaguaí/RJ?
}

O PME articula-se com a democratização do ensino, e logo com a inclusão escolar de estudantes público-alvo da Educação Especial, pois é um elemento central para a consolidação da democracia, da inclusão social e da garantia do direito à educação para todos os estudantes (BRASIL, 2014). Adorno (1995) relata que quem deseja educar para a democracia necessita esclarecer com muita precisão as debilidades da mesma, porque só podemos viver a democracia e só podemos viver na democracia quando nos damos conta igualmente de seus defeitos e de suas vantagens.

Sobre tal perspectiva, professores, pais, mães, estudantes, funcionários, comunidade escolar em geral, precisam oferecer resistência a pseudoinclusão², que distorce o real sentido da inclusão escolar, conservando assim a marginalização e a segregação desses estudantes público-alvo da Educação Especial.

A educação como direito de todos, possui o dever de possibilitar oportunidades de ensino e aprendizagem se adequando as reais condições de cada estudante, pois

\begin{abstract}
Pensando a organização da escola democrática defendemos que, a reflexão ao se discutir a organização da escola que atenda à diversidade dos estudantes, se opondo à segregação histórica de espaços escolares diferentes, sistematizados segundo a ideia de 'capacidade', esta fundamentada em valores amalgamados em preconceitos sobre a concepção de deficiência e da pessoa com deficiência, significa uma educação para a resistência à barbárie. $E$, sobretudo, uma educação para a experiência, inaugurando um momento histórico de possibilidades para a escola. (DAMASCENO, 2010, p.34)
\end{abstract}

Então, fundamentando-nos nas variadas legislações educacionais inclusivas, que dialogam com a diversidade presente na escola contemporânea, iremos pesquisar o PME de Itaguaí/RJ (2015-2025), atentando-nos para o acolhimento dos estudantes público-alvo da Educação Especial.

O Plano Municipal de Educação de Itaguaí/RJ (2015-2025) é intitulado "Educar Para a Mudança - Participação, responsabilidade e ação" e possui 112 páginas, que são organizadas da seguinte maneira: apresentação, contendo a história do município de Itaguaí/RJ e sua análise situacional; Parte 1 - Dados Educacionais Coletados pela

2 Denominamos como pseudoinclusão a falsa inclusão que se faz presente em alguns espaços educacionais/sociais, que consiste em desconsiderar as demandas diferenciadas dos estudantes e/ou indivíduos que fogem do padrão dito normal. A inclusão designa na participação plena de todos, sendo contrária a qualquer atitude discriminatória. 
Secretaria Municipal de Educação e Cultura, apresentando dados estatísticos e informações em relação à educação do município; Parte 2 - Análise dos Indicadores Sistema Integrado de Monitoramento, Execução e Controle (SIMEC), composto por: As Grandes Áreas em Discussão no Plano Municipal de Educação, Metas e Estratégias e a avaliação do PME; o documento também possui três anexos denominados: Anexo I Dados do Sistema Integrado de Monitoramento, Execução e Controle - SIMEC; Anexo II Relatório da Conferência do Plano Municipal de Educação de Itaguaí; Anexo III - Registro Fotográfico do Processo de Construção do PME; e por fim referências bibliográficas.

Em sua apresentação o PME de Itaguaí/RJ além de esboçar que está em consonância com o PNE atual, também destaca tal preocupação com sua municipalidade:

Assim como o PME aprovado pela Lei 2826 de 2009, cabe ressaltar que o atual não é um Plano de Governo, mas um Plano de Estado com propostas alicerçadas na realidade local, na história, na geografia e na demografia do município, ultrapassando, portanto, os limites da política partidária atual ou futura, com a intenção única de traçar metas e estratégias que conduzam a população a melhores condições de vida, por meio da oferta de uma educação escolar qualitativa e igualitária de direitos a todos, conforme garantida e prevista pela Constituição Federal. (PME DE ITAGUAÍ, 20152025, p. 17-18)

Na primeira grande área: Acesso e permanência obrigatória, o PME (2015-2025), de Itaguaí/RJ cita que a orientação pedagógica que direciona as ações das unidades escolares deve estar consolidada nos projetos político-pedagógicos, enfatizando um fazer que proporcione um processo qualitativo de aprendizagem, garantindo assim aos estudantes o ingresso, a permanência e a conclusão no Ensino Fundamental.

Reconhecemos a pertinência do projeto pedagógico, pois trata-se de uma prática democrática, de modo em que todos devem participar de sua elaboração na perspectiva de aprimorar a educação na escola. Damasceno (2010) explica que o projeto pedagógico possui um caráter democratizador e que deve ser elaborado com a participação de todos os interessados na ação educativa, como equipe gestora, docente, discentes e comunidade. Diante disso a Lei de Diretrizes e Bases da Educação Nacional (LDBEN), Lei no. 9394/96, em seu artigo 14, inciso I, afirma que:

Art. 14. Os sistemas de ensino definirão as normas da gestão democrática do ensino público na educação básica, de acordo com as suas peculiaridades e conforme os seguintes princípios:

I- participação dos profissionais da educação na elaboração do projeto pedagógico da escola; 
Porém, Libâneo (2008) nos alerta que por vezes a construção do projeto pedagógico se caracteriza maiormente como uma ação burocrática:

A efetivação da prática de formulação coletiva do Projeto Pedagógico ainda é, na maior parte dos casos, bastante precária. Vigora mais como um princípio educativo do que como instrumento concreto de mudanças institucionais e do comportamento e das práticas dos professores. (LIBÂNEOO, 2008, p.357)

O que não deveria ocorrer, pois o projeto pedagógico age além de um princípio educativo, interferindo no cotidiano escolar em vários aspectos, como por exemplo, no trabalho pedagógico e educacional, na sala de aula e na estrutura da escola. Para tanto, Libâneo et all (2008, p.357) mencionam que: "o projeto pedagógico-curricular é um documento que reflete as intenções, os objetivos, as aspirações e os ideais da equipe escolar, tendo em vista um processo de escolarização que atenda a todos os alunos.". Em resumo, o que consta no projeto pedagógico retrata os horizontes da instituição escolar.

É importante esclarecer que neste estudo, citamos e analisamos somente as Metas e estratégias do PME de Itaguaí que tratam sobre a Educação Especial. É relevante explicitar também que a Meta 4 do Plano Municipal de Educação de Itaguaí possui 31 estratégias que abraçam o público diferenciado que se faz presente na escola contemporânea. Dessa maneira, realizamos uma análise geral frente a Meta 4 e suas estratégias, citando algumas dessas, e debatendo sobre o processo de inclusão escolar de estudantes pertencentes ao público-alvo da Educação Especial.

Na Meta 2 do PME destaca-se: "Garantir, a toda a população de 06 a 14 anos, o acesso, a permanência e a terminalidade no ensino fundamental; que pelo menos $95 \%$ concluam na idade recomendada, até 2025."

Para a implementação dessa meta, o PME de Itaguaí/RJ desenvolveu 29 estratégias. Assim, sublinhamos o incentivo a formações continuadas que pode ser visualizado em diversos momentos do PME (2015-2025).

Outro ponto fundamental que elencamos é a garantia da ampliação da acessibilidade para os estudantes público-alvo da Educação Especial. No entanto salientamos que a acessibilidade não deve ser lembrada somente em sua esfera física/arquitetônica, pois seus outros níveis como curricular e didático-pedagógicas são primordiais para a inclusão ocorrer. Segundo a Norma Brasil 9050 (2004), da Associação Brasileira de Normas Técnicas (BNT), que aborda sobre a Acessibilidade de Pessoas Portadoras de Deficiências 
e Edificações, Espaço, Mobiliário e Equipamentos Urbanos, a definição dos termos acessibilidade e acessível é respectivamente:

3.1 acessibilidade: Possibilidade e condição de alcance, percepção e entendimento para a utilização com segurança e autonomia de edificações, espaço, mobiliário, equipamento urbano e elementos.

3.2 acessível: Espaço, edificação, mobiliário, equipamento urbano ou elemento que possa ser alcançado, acionado, utilizado e vivenciado por qualquer pessoa, inclusive aquelas com mobilidade reduzida. $O$ termo acessível implica tanto acessibilidade física como de comunicação. (BRASIL, 2004, p.3)

Todavia, ainda é notório em muitas escolas brasileiras o descaso com os estudantes público-alvo da Educação Especial, não só materializadas nas variadas barreiras arquitetônicas que dificultam a sua locomoção/transporte, como também obstáculos pedagógicos que não oportunizam a educação para a diversidade. Nesse sentido, Libâneo et all (2008) completa:

Democratizar não significa apenas construir novas escolas. Apesar de importante, só isso não garante o atendimento [...] É preciso ampliar o atendimento e assegurar a utilização de todas as alternativas para garantir o acesso à escola e da garantia de permanência nela, buscar-se-á a construção de um Sistema Nacional Articulado de Educação, de sorte que Estado e sociedade, de maneira organizada, autônoma e permanente, possam, por meio de uma gestão democrática e participativa, atingir os objetivos propostos. (LIBÂNEO, 2008, p.210)

Como enfoca, a instituição escolar somente é democrática quando a mesma pensa/consolida práticas educacionais que considerem toda a sua demanda de estudantes.

$\mathrm{Na}$ Meta 4 juntamente com suas estratégias fica evidente a ênfase na oferta de formações para atuação/docência com o público-alvo da Educação Especial, o que é um avanço, de modo que muitos docentes e outros profissionais da escola possuem dificuldades frente as demandas de um público diversificado.

Entendemos que se faz imprescindível oportunizar espaços formativos para o incentivo de uma práxis emancipada, livre de práticas reprodutoras, pois para educar para a emancipação e autonomia, faz se necessário também professores emancipados e autônomos. Adorno (1995) chama a atenção sobre instâncias formativas implícitas em nossa sociedade, nas quais se opõem à organização para a emancipação de mundo

O motivo evidentemente e a contradição social; e que a organização social em que vivemos continua sendo heterônoma, isto é, nenhuma pessoa pode existir na sociedade atual realmente conforme suas próprias determinações; enquanto isto ocorre, a sociedade forma as pessoas mediante inúmeros canais e instâncias mediadoras, de um modo tal que tudo absorvem e aceitam nos termos desta configuração heterônoma que se desviou de si mesma em sua consciência. E claro que isto chega até as instituições, até a discussão 
http://dx.doi.org/10.5902/1984686X32960

acerca da educação política e outras questões semelhantes. (ADORNO 1995, p.181-182)

Os pressupostos observados no plano municipal instiga que a exclusão vivenciada pelos estudantes público-alvo da Educação Especial seja superada, pois compreendemos ser fundamental o incentivo de formações continuadas sob a perspectiva inclusiva, potencializando aos profissionais da ação educativa ampliação de seus conhecimentos. Corroborando com a implementação de uma escola plural, Damasceno (2010) analisa que

[...] deve-se destacar que esse momento histórico da educação no Brasil evidencia a singularidade de se viver a organização da escola democrática, na qual as diferenças dos estudantes sejam estímulo para os professores desenvolverem novos métodos/estratégias/meios de ensino para permitir a aprendizagem de todos. (DAMASCENO, 2010, p.27)

Sob tal configuração dominadora que nos encontramos, temos que promover espaços onde possamos experimentar experiências formativas democráticas. Apesar de vivenciarmos inúmeros desafios para uma educação de/e para todos.

Com o efeito de concretizar uma educação para a emancipação, de acordo com Adorno (1995), a mesma deve ser dirigida para a contestação e resistência, uma vez que "aquele que pensa, opõe resistência; ainda é mais cômodo seguir a correnteza, ainda que declarando estar contra correnteza" (ADORNO, 1995, p. 208).

Identificamos que o PME de Itaguaí está em coerência com o Plano Nacional de Educação (13005/14), pois a Meta 4 estabelecida no PNE que trata da inclusão dos estudantes público-alvo da Educação Especial, também é encontrada no Plano do Município, sendo coerente com o princípio de superar os desafios rumo a uma educação acolhedora e justa com esse público diversificado. É interessante firmar também que além da Meta 4, encontramos no PME outras Metas com estratégias que oferecem apoio para a inclusão em educação e que estão de acordo com o PNE.

Tomando ciência das demais estratégias que se referem à Meta 4 do PME de Itaguaí/RJ, observamos que os investimentos propostos, como viabilização de tecnologias assistivas, materiais didáticos de apoio, transportes adaptados, mobiliários e equipamentos adequados, dentre outros fatores que colaboram com o desenvolvimento de um cenário escolar mais humano, são essenciais para o processo de inclusão. Nesse contexto, a Declaração de Salamanca (1994) explica a importância sobre o oferecimento de materiais pedagógicos e currículos adaptados

As crianças com necessidades especiais devem receber apoio pedagógico suplementar no contexto do currículo regular e não um currículo diferente. $O$ 
princípio orientador será o de fornecer a todas, a mesma educação, proporcionando assistência e os apoios suplementares aos que deles necessitem. (SALAMANCA, 1994, p.22)

Atentar para um espaço escolar inclusivo é beneficiar não somente os estudantes público-alvo da Educação Especial, mas a todos os que se encontram no espaço educativo, pois conviver com a diferença é importante para a construção de escolas solidárias.

Dentre outras propostas que elevam o direito dos estudantes público-alvo da Educação Especial, atentamos para a implantação de salas de recursos em todas as instituições escolares de Itaguaí/RJ e para as que já possuem, serão disponibilizados mobiliário adaptado, materiais didáticos pedagógicos e equipamentos para atender as especificidades dos estudantes.

O serviço do AEE consiste como um dos meios para democratizar o ensino na medida em que oportuniza a permanência dos estudantes público-alvo da Educação Especial em escolas regulares. Gomes (2007, p.26) completa que a sala de recursos, é o local onde ocorre o Atendimento Educacional Especializado, funciona "para possibilitar a produção do saber e preservar sua condição de complemento do ensino regular (...)" (GOMES 2007, p.26).

Outro ponto que dialoga com o processo de inclusão na/para a escola contemporânea, que se encontra nas estratégias do Plano Municipal de Educação referente à Meta 4, é sobre o bilinguismo, que consiste na oferta da LIBRAS (Língua Brasileira de Sinais) como primeira língua, e como segunda modalidade escrita da Língua Portuguesa, aos (às) alunos (as) surdos e com deficiência auditiva de 0 (zero) a 17 (dezessete) anos, bem como a adoção do Sistema Braille de leitura para cegos e surdocegos, até o final da vigência do Plano Municipal, assim como consta no dispositivo legal

\begin{abstract}
garantir a oferta de educação bilíngue, em Língua Brasileira de Sinais LIBRAS como primeira língua e na modalidade escrita da Língua Portuguesa como segunda língua, aos (às) alunos (as) surdos e com deficiência auditiva de 0 (zero) a 17 (dezessete) anos, em escolas e classes bilíngues e em escolas inclusivas, nos termos do art. 22 do Decreto no 5.626, de 22 de dezembro de 2005, e dos arts. 24 e 30 da Convenção sobre os Direitos das Pessoas com Deficiência, bem como a adoção do Sistema Braille de leitura para cegos e surdocegos. (LEI 13005, 2014, p.8).
\end{abstract}

Precisamos que essas estratégias tenham o compromisso primordial de se implementar em cada escola. Nesta perspectiva, legislações em geral são indispensáveis, entretanto cabe a cada um de nós, protagonistas da educação, nos mobilizarmos para um 
ensino na/para a diferença, onde possamos (re)criar estratégias reais nos contrapondo a manutenção e controle instituído pelo sistema do capital.

Identificamos que o Plano Municipal elabora uma estratégia perante a Meta 6, a fim de acolher os estudantes público-alvo da Educação Especial, ao garantir que as instituições escolares municipais de Educação Básica, em tempo integral, atendam esses estudantes, assegurando-os também o atendimento educacional especializado complementar, ofertado em salas de recursos multifuncionais na própria escola ou em instituições especializadas. (PME DE ITAGUAÍ, 2015-2025)

Nossa análise do atual Plano Municipal de Educação (2015 - 2025) de Itaguaí/RJ nos trouxe elementos que nos permitem afirmar a existência de possibilidades políticopedagógicas de mudanças no que diz respeito ao atendimento dos estudantes público-alvo da Educação Especial, pois o mesmo apresentou disposição em sua reorientação inclusiva no que tange ao atendimento desses estudantes nas escolas regulares do município, avançando com novas estratégias de ensino e fundamentando-se de dispositivos legais que direcionam a inclusão.

Entretanto, longe de sermos ingênuos, sabemos que ainda há muitos desafios a superar, na medida em que a pseudoinclusão se faz presente em muitas classes e escolas regulares, ferindo o direito de estudantes quanto a seu acesso, permanência e sucesso escolar. Desse modo, recorremos ao pensamento de Adorno, no qual nos inspira no desejo de viver uma educação e sociedade emancipada:

\footnotetext{
[...] justamente quando é grande a ânsia de transformar, a repressão se torna muito fácil; que as tentativas de transformar efetivamente o nosso mundo em um aspecto especifico qualquer imediatamente são submetidas a potencia avassaladora do existente e parecem condenadas a impotência. Aquele que quer transformar provavelmente só poderá fazê-lo na medida em que converter esta impotência, ela mesma, juntamente com a sua própria impotência, em um momento daquilo que ele pensa e talvez também daquilo que ele faz. (ADORNO, 1995, p. 185)
}

Posto isso, enfatizamos que a inclusão escolar reafirma a proposta de democratizar o ensino, visto que é contrária a qualquer prática de exclusão. Portanto a inclusão escolar sendo de estudantes público-alvo da Educação Especial ou qualquer outro requer uma reforma ousada na educação, onde o conformismo composto com práticas reprodutivistas, que mantém o ensino homogêneo deve dar lugar ao ensino humano, que acolhe a demanda escolar contemporânea. 


\section{Considerações Finais}

Há de se considerar que pensar no acolhimento de todos e não somente de uma parte da sociedade é determinável para, sobretudo pensar/organizar e, por conseguinte, implementar uma sociedade justa, humana e solidária, visto que uma sociedade de emancipados deve atuar na perspectiva de atender os indivíduos em suas subjetividades, pois

[...] quem defende ideias contrárias à emancipação, e, portanto, contrárias à decisão consciente independente de cada pessoa em particular, é um antidemocrata, até mesmo se as ideais que correspondem a seus desígnios são difundidas no plano formal da democracia. (ADORNO, 1995, 142)

Adorno discorre que no plano formal da democracia existem possibilidades de contradições, visto que sua operacionalidade pode não estar trabalhando conforme seu conceito. Conceito este, que para ser de fato trabalhado, demanda pessoas emancipadas. Adorno (1995) explica que a única concretização da emancipação consiste em que as poucas pessoas interessadas nesta direção, foquem toda a sua energia para que a educação seja uma educação para a contestação e para a resistência.

A reorientação inclusiva presente no atual Plano Municipal de Educação representa uma forte conquista para o processo de inclusão em educação no Município, visto que firmaram o compromisso de desenvolver um sistema de ensino mais democrático e humano. Logo é indispensável que as disposições político-pedagógicas instituídas no PME sejam efetivadas com base nos movimentos instituintes da rede municipal de Itaguaí/RJ.

A Teoria Crítica nos apresenta que para afirmação de uma educação emancipada, os protagonistas da transformação educativa necessitam também se afirmarem como indivíduos emancipados, isto é, capazes de compreender o significado da democracia no ambiente educativo e, quiçá, social. Por conseguinte, torna-se urgente que o Município implemente as variadas diretrizes/perspectivas presente no PME que compactuam com a humanização da escola e da educação.

O movimento inclusivo possui um papel revolucionário, que objetiva romper com raízes excludentes, nas quais perpetuam atitudes e práticas que negam/dificultam a plena participação social dos indivíduos, sejam eles com deficiência ou não.

Reivindicar a inclusão dos estudantes público-alvo da Educação Especial visando condições específicas de acesso, permanência e sucesso escolar (que nada mais são do que seus direitos legais), é a possibilidade de celebrar instituições escolares para todos, 
revestidas de uma educação na/para a diversidade.

\section{Referências}

ADORNO, T.W. Educação e emancipação. São Paulo: Paz e Terra, 1995.

BRASIL. Lei de Diretrizes e Bases da Educação Nacional - LDB n.9394/96 de 20 de dezembro de 1996.

BRASIL. Norma Brasileira. ABNT, 9050. Acessibilidade de Pessoas Portadoras de Deficiências e Edificações, Espaço, Mobiliário e Equipamentos Urbanos 2004.

BRASIL. Plano Nacional de Educação, Lei no 13.005/14. MEC, 2014.

BRASIL. O Plano Municipal de Educação - Caderno de Orientações. MEC, 2014.

BRASIL. Instituto Brasileiro de Geografia e Estatística - 2012. Cidades. Disponível em: http://www.ibge.gov.br/cidadesat/xtras/perfil.php?codmun=330200\&search=rio-dejaneiro|itaguai Acesso em agosto, 2015.

DAMASCENO, A. R. A formação dos professores e os desafios para a educação inclusiva: as experiências da escola Municipal Leônidas Sobrino Pôrto. Dissertação de Mestrado apresentada ao Programa de Pós-Graduação Stricto Sensu em Educação, Universidade Federal Fluminense, p. 80-93, 2006.

DAMASCENO, A. R. Educação Inclusiva e Organização da Escola: Projeto Pedagógico na Perspectiva da Teoria Crítica.Tese apresentada ao Programa de Pósgraduação em Educação da FE/UFF, como requisito parcial para obtenção do grau de Doutor em Educação, p, 30-60, 2010.

GOMES, C. M. A. Feurerstein e a construção mediada do conhecimento. Porto Alegre: Artmed Editora, 2007.

ITAGUAí. Plano Municipal de Educação de Itaguaí: Educar para a Mudança Participação, responsabilidade e ação. Itaguaí - Rio de Janeiro, 2015, 2025.

LIBÂNEO, J. C. OLIVEIRA, J. F. de. \& TOSCHI, M. S. Educação escolar: políticas, estrutura e organização. 6. ed., São Paulo: Cortez, 2008.

UNESCO. Declaração de Salamanca e Enquadramento da Acção. Na área das necessidades educativas especiais. Conferência Mundial Sobre Necessidades Educativas Especiais: Acesso e qualidade. Salamanca, Espanha, 7-10 de Junho de 1994.

\section{Correspondência}

Patrícia Ferreira de Andrade - Universidade Federal Rural do Rio de Janeiro (UFRRJ). Rua: Rodovia BR 465, Km 07, s/n Zona Rural, Seropédica. CEP: Google 23890-000. Rio de Janeiro, Brasil. 


\section{(c) $($ i) (9)}

This work is licensed under a Creative Commons Attribution-NonCommercial 4.0 International (CC BY-NC 4.0) 